\title{
Exploring the intersections: researchers and communication professionals' perspectives on the organizational role of science communication
}

\author{
Kaisu Koivumäki \\ Faculty of Humanities, University of Oulu, Oulu, Finland, and \\ Clare Wilkinson \\ Science Communication Unit, UWE Bristol, Bristol, UK
}

\begin{abstract}
Purpose - This paper reports on research exploring the intersections between researchers and communication professionals' perspectives on the objectives, funders and organizational influences on their science communication practices.

Design/methodology/approach - Examining one context, the inter-organizational BCDC Energy Research project based at five different research organizations in Finland, this paper presents data from semi-structured interviews with 17 researchers and 15 communication professionals.

Findings - The results suggest that performance-based funding policies that drive the proliferation of largescale research projects can create challenges. In particular, a challenge arises in generating a shared sense of identity and purpose amongst researchers and communication professionals. This may have unintended negative impacts on the quality and cohesiveness of the science communication which occurs.

Research limitations/implications - The study was exploratory in nature and focuses on one organizational and institutional environment. Further research with a wider number of projects, as well as funders, would be conducive to a greater understanding of the issues involved.

Practical implications - On a practical level, this research suggests that the creation of clearer communications awareness and guidance may be helpful in some large-scale projects, particularly involving broad numbers of organizations, individual researchers and funders.

Originality/value - This is one of the first studies examining the perspectives of both researchers and communication professionals working over one project, drawing together a range of different institutional and disciplinary perspectives. The results highlight the importance of the influences of funding on science communication aims, assumptions, cultures and structures. The article articulates the need for further research in this area.
\end{abstract}

Keywords Research, Social media, Public relations, Organizational communication, Strategic communication, Communication management, Digitalization, Communication practitioner

Paper type Research paper

\section{Introduction}

In contemporary science communication, a wide range of personal, organizational and social drivers' influence communications that are taking place (Weingart and Joubert, 2019). However, there remains a lack of understanding as to how different organizational and

(C) Kaisu Koivumäki and Clare Wilkinson. Published by Emerald Publishing Limited. This article is published under the Creative Commons Attribution (CC BY 4.0) licence. Anyone may reproduce, distribute, translate and create derivative works of this article (for both commercial \& non-commercial purposes), subject to full attribution to the original publication and authors. The full terms of this licence may be seen at http://creativecommons.org/licences/by/4.0/legalcode.

This study has been funded by the Strategic Research Council at the Academy of Finland, project no. 292854 and the Finnish Cultural Foundation.

Exploring the intersections

Received 21 May 2019

Revised 5 October 2019

9 January 2020

23 January 2020

Accepted 24 January 2020 
$\mathrm{JCOM}$ 24,3

\section{8}

institutional environments shape these drivers in specific contexts, and on the micro-level practices of both researchers and the "in-house" communication professionals who may support them:

In practice, it is individuals or small groups of technical experts who come into contact with publics, not science as an institution or an establishment. And it is therefore the practices of individuals which will frame and shape the communication process (Davies, 2008, p. 415).

Weingart and Joubert (2019) argue research organizations and government departments have been subjected to market-oriented competition for public funds and public attention, resulting in profound effects on how organizations communicate about science. Though influenced by wider science policies, Weingart and Joubert (2019) contend there is a gap between "motives espoused" by science policy and the motives which are then "enacted" by the respective organizations and departments. There is wide variation in institutional public engagement strategies, evaluation, budgets and how it is supported: centralized, distributed and associated with tasks such as marketing or HR (TNS BMRB, 2015) and this institutional transition and confusion may threaten the credibility of science and its communication (Weingart and Joubert, 2019).

In this context and alongside other national and international research policy and governmental regulators who have instigated similar, ongoing processes, the Strategic Research Council (SRC) at the Academy of Finland is one example of a funder who has, since 2015, provided funding to research projects aimed at finding solutions to grand challenges that require multidisciplinary approaches [1]. "Interaction" with society is of key importance during the course of the funded projects, and funding applications must include an interaction plan. The SRC also takes responsibility for projects' follow-up and impact assessments. The study reported here takes this large, pioneering, inter-organizational and temporal research funding scheme as its focus.

Though SRC funding influences only a proportion of the research conducted in Finland, according to Mustajoki (2017) it has an expanded impact on the wider academic community in Finland, where it has increased awareness of the different forms of impact that research may take, and therefore may have strengthened researchers' motivations to embed impactgeneration in the academic process. Such funding is also illustrative of a wider trend throughout Europe, where pursuing improvements in research performance, funders are frequently facilitating more efficient and competitive use of their resources by focusing on the highest performing research groups and mechanisms to draw them together, often "at the cost of institutional block funding" (Zacharewicz et al., 2018, p. 108).

By examining the influence of such new funding regimes, and one of the first SRC funded research projects, this research sought to illuminate a national academic context where changes in views towards science communication and public engagement have the potential to be influenced by new funding instruments. This research is important at a time when there are increasing international performance-based funding policies, which includes communication, engagement and impact activities within their remits and shortages of academic research in this area (Rowe and Watermeyer, 2018). The research also adds to the emerging literature examining the motives of in-house communication professionals (see Casini and Nerisini, 2013; Nærland, 2016; Watermeyer and Lewis, 2018; Autzen and Weitkamp, 2019), and the relationship between them and researchers, which has previously gained little research attention (Borchelt and Nielsen, 2014). As researchers and communication professionals arrive to communication practices from different backgrounds, it is reasonable to assume that there may be differences in their drivers, objectives and practices of science communication which warrant examination (Yuan et al., 2019). By examining the voices of researchers and communication professionals in parallel, as well as the role of funders and organizational 
influences, this research seeks to identify the intersections in their views to science communication practices, on those perspectives:

$R Q 1$. How do researchers and communication professionals identify different sets of normative and deliberative drivers in their science communication practices?

$R Q 2$. How do funders perspectives on the role of communication influence researchers and communication professionals?

RQ3. What role do organizations play in the practices of researchers and communication professionals and their relationships with each other?

\section{Literature review}

2.1 The objectives of science communication

While demands for deliberative openness and interaction are increasing, there is still a gap between science and society (Claessens, 2014; Peters, 2013; Väliverronen, 2015) and public communication or engagement with science and technology has become a feature of both science communication activities and science policy and decision-making. In many countries, researchers are now being encouraged to intrinsically consider the impact of their work within the research process itself. This can include public engagement (Wilkinson, 2017) to the extent that some additional public engagement schemes are now drawing to a close, as engagement is perceived to be embedded within the process of research itself (Watermeyer and Lewis, 2018).

However, there are concerns that the broad variety of functions now attributed to science communication conflate educational and deliberative motives with political motives, such as to promote science and its organizations for public acceptance and to legitimize science policies and public expenditure on science (Weingart and Joubert, 2019; Autzen and Weitkamp, 2019). Although funding's influence on science communication has not received much research attention, it has been found to have an influence on the science communication activities of scholars working in funded programmes (Fähnrich, 2017). Whilst some researchers reject any political intervention and are simply interested in funding, others perceive that scientific objectives and norms need to adapt to political logics (Fähnrich, 2017).

Historically, communicating about science has been perceived by many researchers, not as a voluntary activity, or funding requirement, but as a "duty" and part of the researchers' professional role (Peters, 2013; TNS BMRB, 2015). This sense of duty may imply making the "facts" of research available, increasing enlightenment in society or putting the research organization in a favourable situation (Horst, 2013). Researchers' motivation to participate in science communication has often then been nurtured by the will to ensure information dissemination in society (Karvonen et al., 2014). Although often co-existing, the objective of informing the public about science is still highly ranked amongst research communities over public engagement and dialogue approaches (Heidenreich, 2018), implying the persistence of deficit goals (Cortassa, 2016).

Beyond the individual researcher, the establishments of science, such as universities, research centres and institutes, are increasingly taking on responsibility for the legitimation of the "institution of science" in response to risks associated with organizational reputation, as well as the legitimization of knowledge and expertise in general (Davies and Horst, 2016; Brass and Rowe, 2009).

\subsection{Marketization}

Science communication exists in a wider social, political and economic context, and the changing landscape of knowledge production, along with the neoliberal marketization of science, are altering both institutions and how they consider their own communication
Exploring the intersections 
$\mathrm{JCOM}$ 24,3
(Davies and Horst, 2016). According to Autzen (2014) an organizations' competition for staff, students and funding is sharpened by means of public relations. Whilst, researchers may perceive media visibility as an indicator of the broader impact of their work, and base their judgment of success partly on whether their message has reached funders and the management of their own organization (Peters, 2013).

This may particularly come to the fore with regards to the reporting of "impact". Impact statements are now required by some funders upon application, as well as the evaluation stage of research excellence (e.g. REF in the UK). Impact statements offer potential opportunities to strengthen the value of public communication and engagement, but some researchers may lose sight of the integral role of research itself:

There has been so much talk about impact that sometimes they [researchers] have actually got the message that impact is important but we have to remind them that the REF isn't only about impact, you've still got to get the good [research] papers out first (Wilkinson, 2017, p. 12).

Chubb and Watermeyer's (2017) work examining impact statements in research applications suggest they have prompted strong outcries for the integrity of academics, and the hyperinflation of impact claims may in fact jeopardize the interface between science and society rather than bring the applied benefits perhaps anticipated. According to the literature then, both deliberative and neoliberal ideas are influencing science communication simultaneously.

\subsection{Representations}

Representation implies that science communication is a form of organizational communication, which enacts meaning and at the same time cocreates identities and images of science, scientists, and scientific organizations (Horst, 2013, p. 762).

Davies and Horst (2016) argue that scientists' allegiance is primarily to the disciplines or institutions of science, rather than its organization's and therefore tension may occur between organizations' strategic communication visions, and researchers' identification with their discipline's global practices and values. This echoes far earlier work examining the tensions in scientists' representations, characterizing scientists as "cosmopolitans" and "locals" (Merton, 1973; Bucchi, 2015). The former implies a primary attention to ones' professional goals and peers, the latter infers a commitment to the goals and practices of the organization in which one is based (Glaser, 1963). Research has suggested that the norms of scientific communities towards the role of engagement can be ambivalent, perceptions of peer acceptance for communication activities can vary (Rödder, 2012) and differ based on the mechanism for communication being planned, for example, a dialogue with the public being seen in a more favourable light than media communications (Peters, 2013). Whilst, recent findings suggest that traditional perceptions of scientists normative concerns, their roles in academic and public discourse and sense of professionalism may not represent meaningful drivers of scientists' behaviour to the degree that was expected previously (Besley et al., 2018; Howell et al.,2019). This may be symptomatic of contemporary changes in conceptualizations of the "institution" and "organization" as institutional and organizational boundaries blur. Neoliberal policies are inspiring restructurings and reshapings of organizational units including disciplines, research networks, multi-sectoral groups, as well as universities as institutions themselves (Davies and Horst, 2016). Drawing on organizational theorists, Davies and Horst (2016) describe science communication as a form of "sensemaking" amongst organizations, as the sum of different images of the scientists, universities and other research organizations, tied to their varying organizational cultures. 
Sensemaking materializes in communication, when situations and organizations are "talked" into existence (Weick et al., 2005). Through conscious or habitualized symbolic interaction, communication is a meaning-making practice, which is at the core of constructing the social world, and thoroughly interwoven with various media in the contemporary context (Couldry and Hepp, 2017). As such in order to produce positive communication, organizations may seek to nurture engagement with their employees, to increase the positive potential of their public relations efforts (Kang and Sung, 2017). Specific research projects may then be one example of sensemaking, the creation of a temporary "organization" around a group of researchers, but as yet they have attracted limited research attention especially within the interorganizational, academic context (Karmowska et al., 2017). It is possible then that researchers are balancing different temporal affiliations and identifications to the many projects they are involved with, seeking to convey not only aspects of specific research projects but also their disciplinary and institutional identities and representations.

\subsection{Organizations}

Scientific organizations have increased and professionalized their public relations (PR) efforts for a number of years (Peters et al., 2008), and the incorporation of corporate communication practices into academia is not without its challenges (Davies and Horst, 2016). In the scientific world, PR may be perceived as a "bag of tricks" to dupe potential customers or citizens according to Borchelt and Nielsen (2014), who portray PR as quite the opposite: it is the necessity for continuing the work of an organization through the development of meaningful relationships with the public. Furthermore, they argue that, at the societal level, "PR professionals can help their organizations understand what it means to be socially responsible and help contribute to the ethical behaviour and social commitment of the organization" (p. 66).

The relationship between organizational strategies for public relations, communication professionals and researchers in practice has remained underexplored. This is despite the potential impact this will have on science communication as an enterprise (Borchelt and Nielsen, 2014; Watermeyer and Lewis, 2018). It is also unclear how "strategic" researchers are in their communications. Wilkinson and Weitkamp's (2013) findings support previous notions that researchers remain relatively unplanned in their dissemination strategies, reacting to opportunities for dissemination rather than developing strategies for communications.

One area where there is even more potential for serendipitous dissemination is the online context. The proliferation of online communication (Peters, 2013); creating digital public spheres (Schäfer, 2012), in which organizations, communication professionals and researchers may now operate creates additional contexts for organizations to consider. Mirroring trends in the general population "scholars continue to use social media applications at increasing rates to consume and disseminate information" (Bowman, 2015, p. 34). However, mediatization of science, in respect of online media is unclear (Trench, 2012). Reports on the percentages of the researchers' using social media vary (Veletsianos et al., 2018), and there is no single definition as to what social media should comprise (Lo and Peters, 2016; Lomborg, 2017). Furthermore, knowledge and understanding of the strategic role of social media in communication work is still developing (Tench et al., 2015).

Nevertheless, researchers apparently believe that by promoting public visibility, social media enhances funding and career opportunities (McClain and Neeley, 2014): "And this may mean that what shows up in social media such as Facebook, YouTube, blogs, and Twitter increasingly matters to scientists" (Koh et al., 2016, p. 189). Organizations also share such a view that employees are an invaluable resource for organizations' public relations in terms of the social media connections they may have at their fingertips (Aula, 2016). Employees may strategically tweet about the organization, and daily work activities, contributing to

Exploring the intersections 
$\mathrm{JCOM}$ 24,3

\section{2}

organizational reputation as digital ambassadors (Dreher, 2014; van Zoonen et al., 2014). Yet still from a science communication perspective, little is known about how this might occur.

Ancillary to such efforts are an emerging sector of science communication professionals, seeking to support not only organizations' PR but also to craft platforms for participation between stakeholders and researchers. Digital communication raises new opportunities for communication professionals to work with community needs and dynamics (Kennedy and Sommerfeldt, 2015; Overton-de Klerk and Verwey, 2013; Phillips and Brabham, 2012), but can also create a lack of clarity as to where responsibility for public communication and deliberative activities may lie between research organizations, communication professionals and researchers (Casini and Nerisini, 2013).

In sum, the many intersections related to how science is communicated; the objectives for communication, marketization, the role of representation and organizational communications, as well as the context of increased access to social media, mark the everyday practices of the university communication or public relations office, as well as the researchers they work with. And it is these intersections which this article seeks to further explore.

\section{Method}

\subsection{Research context}

This research focuses on the inter-organizational BCDC Energy Research project (2015-2021) based at five different academic organizations in the north and south of Finland. Funded by the SRC, this interdisciplinary research project on renewable energy involves approximately 40 researchers and 15 communication professionals across five organizations. The SRC funds research that is likely to have societal impact and the strategic research themes are approved by the Finnish Government. The projects' interaction plans must describe the goals, means, stakeholders and implementation of the interaction activities in detail, including social media. Every six months, the metrics on the activity and scale of the funded projects' research and interaction activities and impact narratives are monitored. The SRC develops impact evaluation with the European Commission and peers, such as the UK's Research Excellence Framework (REF) [2].

The BCDC Energy Research project's science communication activities were organized across its five work packages (WP) emphasizing researchers' tweeting and blogging, with the support of the communication professionals in their affiliated home organizations, including one of the article authors (KK). A loose network of these communication professionals was established to provide support for this project amongst numerous other projects partnered by their organizations. The majority of researchers had no previous experience in blogging or tweeting in their professional roles.

\subsection{Research design}

This article presents analysis of semi-structured face-to-face interviews with 17 researchers and 15 communication professionals. The research builds on a critical realist understanding that "although many things are real, they are real in different ways" (Fleetwood, 2005, p. 199; Karvonen, 1999). In critical realist science, the tentative disclosure of the world's configurations underlying the inquired phenomena is the aim, and qualitative research techniques are employed in accordance with the specific objectives of the study (Sousa, 2010). As the research questions are focused on researchers and communication professionals' views, the interview method was deemed appropriate to achieve this objective, with the intention of generating interviewees' accounts of their perceptions, understandings and interpretations (Mason, 2004). A sequence of questions was planned in advance, which still 
allowed the flexibility to follow up particular areas and unexpected themes to emerge (Mason, 2004). Accordingly, the interactional interview dialogues followed the different interviewee's perspectives, reflecting Kvale and Brinkmanns (2009) argument that: "the process of knowing through conversations is intersubjective and social, involving interviewer and interviewee as co-constructors of knowledge" (p. 18). The dialogues were ethnographic interviews in the sense that they followed an ongoing relationship and contact in the field, whereby the interviewer was herself involved in the wider project, extending the possibilities for rapport between the parties (Mason, 2004).

Engagement with existing literature primed the interview topics, and questions about the research projects were guided by the interviewer's knowledge of the context. A prequestionnaire contextualizing the interviews and the interview guide was inspired by previous science communication studies and structured around main topics: the aims, norms and values of science communication; and participation and support. The guide included the science communication experience of the interviewed researchers, their perceptions of representing various organizational aspects (Horst, 2013), and norms and social goals of science communication (Dudo et al., 2014). It included questions such as "What should the goals of science communication be like in society?" and "For what purposes should researchers in general use online/social media?" Additionally, concepts such as "branding" and "representation" were discussed. The questions were similar for both groups, though the communication professionals were also asked about the relationship between the research projects and their organization's communications. The pre-questionnaire was not meant to function as an exhaustive list or quantitative data, but served as a thought-provoking tool for the interviews and as such is not included in the analysis.

In a qualitative approach, research aims for sensitivity instead of objectivity, recognizing that professional knowledge may blind or enable researchers' analytical apparatus to see connections within the data (Corbin and Strauss, 2015). In order to raise confidence in this study's interpretations, declarations of the author's (KK) involvement with the group and inevitable subjectivity is acknowledged. Therefore, the interpretations can be affected by biases, and a reflexive approach, and development of the analysis and article with a co-author (CW) who has no involvement in the BCDC Energy Research project, sought to allow for an additional degree of validation.

\subsection{Recruitment}

All the interviewed researchers $(n=17)$ were project members that had participated in the project's communication activities by blogging or tweeting. Their fields included the sciences, social sciences and humanities (SSH), economics and information technology (IT) from a range of different research organizations as presented in Table 1. Five of them were professors or leaders of their research units or the project's WPs, four had post-doc positions and eight were doctoral or project researchers, and comprised five nationalities.

\begin{tabular}{|c|c|c|c|c|c|c|c|}
\hline & University 1 & University 2 & Centre 1 & Centre 2 & Centre 3 & Others & \\
\hline Economics, WP1 & 2 & & 2 & & 1 & & \\
\hline IT, WP2 & 2 & & & & & & \\
\hline Sciences, WP3 & & & & 3 & & & Table 1. \\
\hline IT, WP4 & & 4 & & & & & Interviewees \\
\hline SSH, WP5 & 3 & & & & & & disciplines and \\
\hline Communication Professionals & 3 & 2 & 1 & 2 & 2 & 5 & affiliations \\
\hline
\end{tabular}

Exploring the intersections 
$\mathrm{JCOM}$

24,3

214

Although we detected some differences between disciplines, professional age of the interviewees and by gender, more detailed characterizations were not the focus of this research, as for example disciplinary differences are well researched elsewhere (see e.g. Peters, 2013).

The interviewed communication professionals $(n=15)$ had positions which varied from supporting communication roles alongside their core tasks, to full-time communication officers, and half of the professionals were in managerial roles. Their affiliations are presented in Table 1 . All were connected to the project, and together form a group of interviewees that may be characterized as representatives of an organizational science communication ecosystem. The group represents all of the interviewed researchers' affiliated universities and governmental research institutes at the levels of faculties, centres and central communication units, as well as interviewees from a peer project, strategic partner, associated science communication agency, funding body and the Finnish Government. Three of these professionals also had other positions as researchers. Interviews lasted on average for nearly two hours (54-132 $\mathrm{min}$ ) and were held at their place of work or in workplace coffee rooms, during June-August 2017.

\subsection{Analysis}

All of the interviews were conducted and audio-recorded by the author (KK), two of them as video calls, the majority in Finnish and three in English. Interviews were transcribed verbatim by an assistant. Thematic analysis was used as a method for identifying and analysing patterns of meaning, and the ways broader social contexts impinge upon those meanings (Braun and Clarke, 2006; Clarke and Braun, 2014). Although existing conceptualizations were used to organize data into codes, insights deviating from existing literature drew analytical attention and generated clusters of codes that assisted in the construction of major and sub-themes.

The article combines the descriptive and conceptual levels of thematic analysis to examine the underlying ideas in order to interpret, organize and make interconnections between themes, with conclusions drawn from across the whole analysis (Braun and Clarke, 2006; Clarke and Braun, 2014). The analysis process involved iterations between the empirical data and existing theory, and through revisions of the original codes and their interrelations (including in discussion with the second researcher, $\mathrm{CW}$ ), key themes were identified. Coding of the objectives of science communication was anticipated from the research literature, as well as the role of organizations as to what the researchers prefer representing. We inductively analysed the emergent patterns clustering around the flexibility of organizational structures and underlying conceptualizations such as duty. The role of funders was also identified as relevant during inductive coding.

Working systematically with a large data set was managed with NVivo and memowriting (Corbin and Strauss, 2015). The authors did not seek to determine the reliability of the coding frame with inter-rater reliability scores, as coding was understood as an active and reflexive process, with no one correct procedure, therefore the analyses inevitably bears the mark of the researcher who conducted the initial analysis (KK) (Clarke and Braun, 2014).

\section{Results and discussion}

Analysis of the interview data identified 27 codes, grouped by three key themes: the objectives of science communication, the role of funders and the role of organizations. 


\begin{tabular}{|c|c|c|c|c|}
\hline & & Researchers & $\begin{array}{l}\text { Communication } \\
\text { professionals }\end{array}$ & $\begin{array}{l}\text { Exploring the } \\
\text { intersections }\end{array}$ \\
\hline \multirow[t]{4}{*}{$\begin{array}{l}\text { The objectives of science } \\
\text { communication }\end{array}$} & $\begin{array}{l}\text { Deficit style } \\
\text { informing }\end{array}$ & Remaining factual (8) & $\begin{array}{l}\text { Explaining and inspiring } \\
\text { interest (8) }\end{array}$ & \\
\hline & $\begin{array}{l}\text { Legitimization of } \\
\text { science }\end{array}$ & $\begin{array}{l}\text { Transparency and equality } \\
\text { (11) }\end{array}$ & $\begin{array}{l}\text { Building trust and science } \\
\text { visibility (10) }\end{array}$ & \\
\hline & & $\begin{array}{l}\text { Science in a post-truth, } \\
\text { online era (7) }\end{array}$ & $\begin{array}{l}\text { Supporting funding and } \\
\text { rationality (7) }\end{array}$ & 215 \\
\hline & $\begin{array}{l}\text { Engaging in societal } \\
\text { debate }\end{array}$ & $\begin{array}{l}\text { Reacting to alternative } \\
\text { truths (8) } \\
\text { Participating in media } \\
\text { discussions (7) }\end{array}$ & $\begin{array}{l}\text { Engaging with society for } \\
\text { impact (16) }\end{array}$ & \\
\hline \multirow[t]{3}{*}{ The role of funders } & $\begin{array}{l}\text { Role in academic } \\
\text { practice }\end{array}$ & $\begin{array}{l}\text { Funding and peer pressure } \\
\text { (37) } \\
\text { Role in grant applications } \\
(8)\end{array}$ & $\begin{array}{l}\text { Provokes science } \\
\text { communication (15) } \\
\text { Tracking impact (6) }\end{array}$ & \\
\hline & Scepticism & $\begin{array}{l}\text { Source of frustration and } \\
\text { competition (10) }\end{array}$ & $\begin{array}{l}\text { Source of frustration and } \\
\text { competition (13) }\end{array}$ & \\
\hline & Positive outcomes & $\begin{array}{l}\text { Reaching beyond the } \\
\text { "Ivory Tower" (7) }\end{array}$ & $\begin{array}{l}\text { Importance of science } \\
\text { communication (15) }\end{array}$ & Table 2. \\
\hline \multirow[t]{5}{*}{ The role of organizations } & Flexibility & $\begin{array}{l}\text { Situationally and variably } \\
\text { (30) } \\
\text { Researchers autonomy (8) }\end{array}$ & $\begin{array}{l}\text { Situationally and variably } \\
(20) \\
\text { Researchers autonomy } \\
(13)\end{array}$ & $\begin{array}{l}\text { Themes on the } \\
\text { objectives of science } \\
\text { communication, the } \\
\text { role of funders and the }\end{array}$ \\
\hline & & $\begin{array}{l}\text { Representing researchers } \\
\text { (27) }\end{array}$ & $\begin{array}{l}\text { Representing researchers } \\
\text { (8) }\end{array}$ & $\begin{array}{l}\text { role of organizations. } \\
\text { The shading and }\end{array}$ \\
\hline & & Creating a "brand" (52) & Creating a "brand" (30) & $\begin{array}{l}\text { broken lines indicate } \\
\text { when a code was }\end{array}$ \\
\hline & & $\begin{array}{l}\text { Duty vs. collective } \\
\text { responsibility (37) }\end{array}$ & $\begin{array}{l}\text { Duty vs. collective } \\
\text { responsibility (11) }\end{array}$ & $\begin{array}{l}\text { shared by both } \\
\text { researchers and }\end{array}$ \\
\hline & $\begin{array}{l}\text { Demands on } \\
\text { resources }\end{array}$ & $\begin{array}{l}\text { Increasing communication } \\
\text { expectations (34) }\end{array}$ & $\begin{array}{l}\text { Breadth and length of } \\
\text { projects (56) }\end{array}$ & $\begin{array}{r}\text { communication } \\
\text { professionals }\end{array}$ \\
\hline
\end{tabular}

\subsection{The objectives of science communication}

In response to research question 1, "How do researchers and communication professionals identify different sets of normative and deliberative drivers in their science communication practices?", the results indicate objectives for science communication, which can be grouped according to both dimensions of deficit and engagement modes (Heidenreich, 2018), as well as the legitimization of scientific practices. Deficit style informing continues to remain important, as the science communication research literature has long stated (Wilkinson et al., 2010), and both researchers and communication professionals alike clearly identified it in their discussions. When talking about social media use, they discussed the balance between accuracy and presenting research, which may still be tentative or ongoing as a response to the funders' expectation of communication throughout the course of the research process:

Researcher 24, economics: "These tweets are not declaring any peer-reviewed results, and undoubtedly in this new world, highlighting one's research topic implies its importance. Eventually we come to the fundamental questions of distinguishing opinions from facts."

Researcher 24 questions a role to present the "facts", but also opportunities to do this before any research findings have been published or peer reviewed which could juxtapose facts with opinions. Prior research has introduced varying meanings of legitimization (Borchelt and Nielsen, 2014; Peters et al., 2008). In these results, legitimization of science also formed a reason for the growing expectations for transparency and dialogue with the public (Väliverronen, 
$\mathrm{JCOM}$ 24,3
2015). According to some interviewees, legitimization includes shaping and improving the distant public image of science, science's importance and value particularly in the post-truth era when other social forces may come to the fore. In line with previous studies, researchers frequently discussed the need to diminish the gap between intrascientific practice and public representations of science (Peters et al., 2008) critiquing the minor role scientists sometimes play in online debates (Schäfer, 2012). Concurrently, there was also concern amongst researchers that the means of science communication should be well chosen and not simply react to online discourses, again drawing on the importance of a "factual" basis:

Researcher 16, sciences: "A lot of the decision-making may be based solely on impressions or images calling the shots... Either one must play along or not play at all. And - we probably must play, but by the terms of science, not lowering to what's typical in the revisioning of images, but affecting the images with facts."

There was also evidence of a sense of shared responsibility amongst the academic community to be engaging in societal debate, in a dialogical fashion (Heidenreich, 2018), for example, by providing scientific knowledge of use to current environmental debates which might be happening online or to show how public funds are being used:

Researcher 14, sciences: "Today's people are more and more aware of these things [expert knowledge], so that a researcher can't stay perching in his office. It's important to make science visible, and also show what the public money is spent on, not just into somebody's pocket as salary, but what use did it make?"

In the same way that researchers could not avoid public conversations, to stay "perching" in their offices, they were also beholden to participating in digital conversations, although this was described as rather reactive and unplanned (Wilkinson and Weitkamp, 2013). The researchers tended to limit their participation to situations which were also perceived to be worthwhile to them, with some stating that a more provocative role should sometimes be taken:

Researcher 3, economics: "It's probably not a new phenomenon that all sorts of knowledge is out there, but now it's easier to get with all the digital technology. - It's extremely important that science communication is active in the sense of engaging in the discussion and not just telling that we have some result, but even shut down the tweets of an interest group about a report of their initiative stating that my oh my, $1+1=3$. Science communication has the role to publicly state that actually $1+1$ still equals $2 . "$

Similar normative objectives revealing concerns regarding science and society relations were identified amongst communication as well as researchers, often intertwined with a logic that there is a need to defend and support rational thought, and to build trust in the scientific process. By making it visible, so that decision makers appreciate the value of science, they are able to continue to offer funding support. The professionals made stronger statements than the researchers about engaging with society for impact and the need to build trust, echoing previous findings that "communication scholars prioritize "showing that the scientific community cares about society's well-being' higher than scientists" (Yuan et al., 2019, p. 115). This may be due to the professionals' increased awareness of the external communication environment and perceived changes to the public reception of the epistemic authority of science (Cortassa, 2016).

Communicators stressed the importance of scientific knowledge in decision-making, framing knowledge as a "service" to stakeholders, including businesses. Furthermore, the communicators regard science communication and impact creation as the very justification for the use of societal resources on science spending, as well as their own narratives as to what legitimate scientific work might look like: 
Communicator 32, government: “I don't know how orthodox this is, but I think the task of science, when successful, is to bring order to the chaotic world. To bring out a pattern of order from somewhere in the chaos and create a direction of where we are heading, find trends, find long trajectories, and so remove the chaos where we are all the time."

Communicator 18, institute: "One thing is funding, but behind funding and all of this [changing drivers for science communication] is the impact. I do believe that researchers have also reached the understanding by now that generated knowledge is not necessarily impactful in any way if it is not taken somewhere where it could be used."

In this sense, the communication professionals included in this research, appeared more concerned with management of the wider scientific trust portfolio, by enhancing trust for the entire scientific enterprise beyond one's own organization (Borchelt and Nielsen, 2014), than to legitimizing their own organization or researchers alone (Peters et al., 2008). Rather than being driven by neoliberal mediatization and marketization, a prevalent concern amongst the existing science communication literature on science public relations and engagement (Weingart and Joubert, 2019; Besley et al., 2018, Watermeyer and Lewis, 2018; Nærland, 2016; Marcinkowski et al., 2014), communicators' attentions appeared more preoccupied with future research prerequisites, ethical responsibilities (Forementin and Bortree, 2018) and the socio-cultural role of public relations beyond organizational boundaries (Edwards, 2018).

\subsection{The role of funders}

The role of funders in the context of science communication was widely discussed in the interviews, often unprompted, suggesting, in response to research question 2, that funders' perspectives on the role of communication is having a considerable influence on researchers and communication professionals alike. The arising themes included both neoliberal marketization influences on cultures and communication practices (Davies and Horst, 2016), and desires for impact-generation (Chubb and Watermeyer, 2017; Wilkinson, 2017) within the comments.

Although some comments reflected a neutral view on the funders' role in academic practice, with funders simply an inevitable aspect of the researchers' experience, it was also apparent that some interviewees were responding to a perceived requirement for science communication. Without a great deal of problematization, the researchers described creating a reputation around projects or brands as means for striving towards continued funding illuminating how contemporary market-driven ideologies have been re-shaping academic cultures and thereby communication (Bucchi, 2015; Davies and Horst, 2016). Many researchers perceived visibility and digital presence as an existential matter resembling the findings of Scheu and Olesk (2018), whereby they discussed comparing their own actions with their peers' activities on social media. However, there was also wariness that the expectation of communication at all stages of the research process may lead to the production of empty, artificial contents, the creation of an "image" of scientific labour:

Researcher 25, economics: "And in the background, there's the idea that ok, should one appear there [in social media] to better secure the future funding. So it is kind of harsh, and has not at all to do with doing science but the resources and creation of an image about 'oh goodness' how diligent and hardworking they are."

These practices build attitudes and working cultures for science communication online resembling the findings of Marcinkowski et al. (2014) where researchers' willingness to go public was influenced by organizational aspects. However, in the present case, the influence originates in the perceived funding policies' expectations, as well as perspectives about peers, rather than organizational agendas, displaying a shift in the systemic structure of academia,
Exploring the intersections 
$\mathrm{JCOM}$ 24,3

\section{8}

which is then playing out directly at the micro-level of researchers as digital science communicators.

Scepticism was a small but important theme regarding the funder's interest to follow up on the activity of grant holders, as well as comments reflecting the "artificial" nature of communication sections in grant applications. Professionals pointed to lightly written and audited communication agendas (Watermeyer and Lewis, 2018), weathering the academic community's respect for science communication, in a similar vein to the views expressed around the artificiality of some impact statements (Chubb and Watermeyer, 2017). This could become a source of frustration and competition, whereby academic competition for resources may drive visibility attempts, and the creation of images to secure funding, which can feel in conflict with the traditional scientific discovery discourse. Interviewees often implied frustration over this constant cycle to justify resources, and the desire to promote a positive image:

Researcher 6, IT: "A challenge for science communication is that most of the scientific results are, in a way, pure nonsense - that doesn't have any practical meaning. Some of it is important, but most of it is just to keep the wheels turning. - The point is not that we try to communicate what we have done, but to create a positive image of it, so that the state won't cut up the funding streams. This may be harshly pragmatic."

Such quotes express a sense of scholarly concern regarding mediatization's and marketization's influence on the core processes of science and on science communication, as has also been documented in Norway (Nærland, 2016), Estonia and Germany (Scheu and Olesk, 2018). This also raises questions as to how effectively researchers may be able to balance competing purposes for their communication practices. Weingart and Joubert (2019) discuss the need to maintain distinctions in promotional and educational objectives in order to uphold the integrity of science communication, but that such distinctions can easily blur, a danger which is perhaps even more apparent in flexible, unplanned and reactive spaces such as digital and social media communication.

In contrast, professionals' views did not directly relate to funders in the same way. They describe the research organizations' need to secure their existence via competition for budget monies, project funding and students, which are amongst the reasons they strive for their organizations' media visibility. Funding is integral in this context, but was perhaps one step removed in such justifications. From a professionals' perspective, there were positive outcomes and influences from the funding bodies' promotion of science communication. The professionals embraced the funders' goals for societal impact, seeing the drives for scientific knowledge and results beyond the university as constructive, promoting and coercing increased science communication amongst the Finnish academic community and furthering resources:

Communicator 33, project: "It's the funding that made this [science communication] possible. - There is no way I could see this realizing into any greater action without this funder. - Researchers are positive - not just fulfilling another funder's requirement but quickly creating positive practices implying that researchers support this. And they really take the action."

The funding bodies' aspirations are also understood in deliberative ways and welcomed, particularly by communication professionals, as they already have a tendency to ally with the funding bodies' communication aims and demands due to their professional roles. In contrast to previous research which has suggested such funders pressures are ineffective (Heidenreich, 2018), these findings suggest that the funding bodies' incentives are able to influence science's communication and exert influence over that communication far more powerfully than the communication units would otherwise be able to apply alone. 


\subsection{The role of organizations}

The final theme explores research question 3, "What role do organizations play in the practices of researchers and communication professionals and their relationships with each other?" The organizational connections represented in researchers' communication drew out varying layers and reasonings, which often contradicted. The affiliation of the research centre, university or discipline was frequently mentioned as the primary representation, albeit in a range of different combinations. Therefore, changing structures of faculties, projects and funders meant these were not the priority for many, an experience found in prior research which suggests researchers working on multiple projects can face difficulties in reconciling temporary goals and identities (Karmowska et al., 2017). Amongst interviewees, the organizational representations were therefore governed with flexibility. For some, use of different identities is linked to a sense of affection, such as a feeling of belonging to their university, or respect for their disciplinary community, whilst for others, the obscurity of one's discipline, organization or its units or the funding body's political background may have negative connotations:

Researcher 30, SSH: "I can talk about the research area that I have worked on no matter which faculty it may belong to at the time. Or the research may belong to many different fields and the funding bodies may change. I would represent science in general because of course I am a very scienceaffirmative person."

Researcher 25, economics: "I have even triple roles: I was recently about to speak at a conference, and as I saw their programme where I was introduced as representing the [name] centre, I immediately reacted that I don't want to represent that; that's not where I'm coming from. I wished that my other organizations had been mentioned. Okay, that centre pays my salary - and the organizer regarded the centre's image as selling."

The interviews made clear that the connection to the organization is often weak, particularly amongst university researchers, where individual autonomy is strong. This also meant that some researchers choose to update their profiles entirely outside of the organizations' website. Similarly, in juggling funders, projects and programmes some researchers were happy to identify and support a group which had been consciously branded, and which may outgrow the affiliation they feel to the university as a whole:

Communicator 33, project: "Those units are part of the larger organization, but terribly autonomous, and don't identify with the larger organization under whose management they actually are. Anything can happen there, but since they have the money, the faculty can do nothing. When [an external] funder is paying your salary, not the university - you identify with nothing but the projects that last for a while, freely scanning for the next project. The current project-based funding policy is totally messing up the management."

Whilst this may lead to strong cohesiveness in individual projects, it could also have negative connotations, with some researchers seen to be operating outside of the universities altogether:

Communicator 15, university: "I have noticed that many researchers don't even know that they work for the university. They have a belief that they work for some professor in some project."

And this could contribute to the sense that some scholars have to communicate in order to "sell" themselves, as academics become disconnected from an organization and professional sense of identity (Chubb and Watermeyer, 2017). Researchers were aware of, and didn't necessarily reject "branding" as a means of science communication, considering it useful for many reasons, including meaning-making and being open to practices which would make their digital identities more visible (Bucchi, 2015): 
$\mathrm{JCOM}$ 24,3
Researcher 26, IT: "It it's kind of creating an identity or an image maybe - An identity for your project, whatever that thing is, in a way that you want it to seem, maybe successful - which way you want to brand your thing. So I guess trying to create something, some identity for your project."

Professionals were, however, more reserved in their favouring of explicit branding in an academic context. Some consider it as a necessity for the scientific community, to be "branded" as reliable advocates of "facts" and knowledge to be heard amongst all the voices online. A number of communicators identified that they could not explicitly request researchers to highlight organizations, but did discuss requesting this so that there was some link and consistency in how an organization's work was being shared:

Communicator 8, centre: "Then I have usually asked, when I'm tweeting from our [name of the centre] account: 'Would you please add to your profile that you are our researcher, otherwise it would be silly that we randomly retweet somebody's tweets who can't be recognized as our researcher?' Then they [researchers] usually go 'Oops, I totally forgot to mention that'."

The strategic role of social media is still in its developing phase (Tench et al., 2015), so for communication professionals allying researchers' profiles with an academic organization suggests reliability of an actor in the digital sphere and one small step towards more consistent messaging. One researcher described a similar tactical role choreographed with her research centre's communicator reflecting previous literature on researchers' (Koh et al., 2016) and employees' (Dreher, 2014; van Zoonen et al., 2014) strategic social media use:

Researcher 3, economics: "It's not my job to follow the media monitors, but our communicator is clever to spot topical issues, and notifies me with direct messages in Twitter. The topic may not be suitable for commenting from our organization's profile that she runs, but fits my role as the expert."

It was also apparent that the sense of "duty" some researchers describe having in relation to wider communication activities (Peters, 2013; TNS BMRB, 2015) has not yet transferred into either the motivational attempts' of the professionals to encourage engagement with digital media or the responsibilities a researcher felt. Expectations had not always reached researchers, not knowing what was expected in terms of blogging or social media, leaving them the autonomy to react to the expectations in varying ways and dependent on who was asking:

Researcher 36, IT: “If my fellow colleagues say 'Ok, post your things on Facebook,' then I do. If the one who pays me tells me to do it, I generally do. If the faculty that gives me a place to sit - I can say 'Yeah, I'l do it later.' And then maybe in one month. I think that the researchers in general do it this way".

This lack of consistency around communication expectations in part could be due to a sense of dispersion amongst the projects an organization might partner in with varying communication independencies and demands on resources. However, the shortness and proliferation of projects may also make it difficult to gather publics and followers, and to generate recognition and impact, thus strengthening the tendency to focus on short-term objectives, often superseding the drive towards larger societal goals (Besley et al., 2018). Whilst acknowledging the multifaceted nature of academia, some communicators worried that this dispersion could be perceived as fragmentation of scientific knowledge and impact on public awareness and legacy:

Communicator 31, university: "Also, as a citizen I wonder what is the sense for a project lasting a couple of years to create a brand, why does it exist? - Projects don't have enough time to reach recognition, and unfortunately won't stay in the mind of the public. What exactly of the created capital is left behind when the project ends? The web is probably full of corroded sites. This all appears as turmoil." 
All in all, for the interviewees, the organizational representations appear optional. They may be chosen situationally and tactically and are not consistently volunteered. This seems to go beyond conceptualization of organizational or institutional identities underlying representations (Davies and Horst, 2016) as well as organizational or institutional norms (Besley et al., 2018; Howell et al., 2019), and local or cosmopolitan goals (Glaser, 1963). Instead, the optionality seems to point to social media for professional, personal and reputational purposes (van Zoonen et al., 2014) and to so medialization (Aula, 2016), whereby researchers take on situational, multiple identities, making digital identity a muddled interaction of perspectives, within academic processes with various contextual factors at play (Grand $e$ t al., 2016; Heap and Minocha, 2012).

\section{Conclusion}

This study focused on researchers and communication professionals based in one interorganizational, temporal large research project in Finland, which sought to include digital communication and impact within its remit. The study was exploratory in nature, and its findings are not intended to be representative of other research projects, instead, this qualitative study seeks to broaden understanding of how science communication was constituted and operated in one organizational and institutional environment.

In relation to research question one "How do researchers and communication professionals identify different sets of normative and deliberative drivers in their science communication practices?" varying perspectives are apparent. Researchers and communication professionals identify subtly different sets of normative and deliberative drivers in their science communication practices, though underpinning these differences are shared notions of deficit, legitimization and the need to engage in societal debate. The legitimization of science is a key feature where researchers are increasingly being called upon to participate in social media discussions in the contemporary era of alternative truths (Howell et al., 2019), albeit often reactively, and without a strategic eye. Communication professionals hold more deference towards an ethical or moral responsibility to address topics, which are of heightened public attention, playing a role in cultivating public trust in science and technology beyond one organization's stakeholders (Borchelt and Nielsen, 2014). These findings suggest there is a need for increased understanding of the finely different, but shared reasons for science communication expressed by researchers and communication professionals, and that any organization seeking to more firmly establish science communication practices within its boundaries may wish to conduct some foundational work to develop a clear understanding as to the motivations for communication amongst its staff.

In terms of research question two, "How do funders perspectives on the role of communication influence researchers and communication professionals?", funders appear to be influencing the aims, assumptions and cultures for science communication, at both organizational and individual levels, sometimes bypassing the academic structures and organizations in which researchers are based, previously seen as a major influence on researchers' media efforts (Marcinkowski et al., 2014), and thereby implying a structural shift. In some cases, funders' influences appear to be accepted as the "new normal", whereas others seem to perceive them as having a somewhat artificial nature, for example, in the case of grant applications and monitoring. The danger here is that this may lead to an overhyping and marketization of research, as well as a decrease in the academic community's respect for science communication. At the level of individual actors, researchers and communication professionals, we see interrelationships amongst research institutions, funding bodies, the market and digital media spaces playing out (Cheek and Øby, 2019; Nærland, 2016). These conditions may again blur the objectives of communication and threaten their perceived
Exploring the intersections 
$\mathrm{JCOM}$ 24,3

integrity (Weingart and Joubert, 2019), as well as place new demands on communication professionals to act as organizational "gatekeepers". Communication professionals appear to support funders' societal aims and find funders' incentives a particularly helpful tool to compel science communication activities (Nærland, 2016) but again, there is the threat that this leads to misunderstandings between researchers and communication professionals when they seek to work together.

Finally, in terms of research question three "What role do organizations play in the practices of researchers and communication professionals and their relationships with each other?" there are once again some variations. Researchers' organizational representations were optional and flexible due to the shifting, temporal organizational affiliations, meaning digital identities can become muddled (Grand et al., 2016; Heap and Minocha, 2012). Numerous research projects are operating with competing agendas, often dispersing rather than drawing together key messages, and researchers also have their own sense of what is right and the most appropriate for them. The shortness of projects and affiliations may strengthen the tendencies to focus on serendipitous rather than strategic communication (Wilkinson and Weitkamp, 2013). In amongst this mix communication professionals seek to "sense-make" their communication efforts (Davies and Horst, 2016) to create links, in order to create some level of clarity for the publics and the stakeholders who are consuming it. As digital science communication grows, and the funding of large scale, inter-related research projects shows no signs of abating at an international level, the relationship between organizations and the researchers who represent them, is worthy of continued research.

This research has limitations, it focussed on one project, in the context of one country's funding regime, and further research on the context and organizational factors at play more widely is warranted. Instead it offers a starting point for critical reflection on the issue of organizational structures, mediatization and the role of funding infrastructures. The research suggests there are grounds for future research on communication professionals' roles, both in research organizations and in working with researchers, particularly in social media and digital contexts, as well as on a greater range of disciplinary areas and foci. In addition, to build a more complete picture, it would be useful to conduct further investigation with funders about intentions, practices and impacts of science communication, from their viewpoint.

Nonetheless, these results suggest that the general effect of changes in the way in which public communication and engagement, is perceived, defined and funded within academia, may create challenges in generating a shared sense of purpose and identity amongst largescale research projects involving numerous organizations and researchers. This may result in the presentation of fragmented images of research to the public and cause unarticulated differences in the intersections between researchers and communication professionals.

On a practical level, greater coordination between funding bodies and research organizations could potentially be helpful to decrease the fragmentation of science communication. The creation of clearer awareness and guidance, and widening of the types of theoretically focused topics in science communication training (Besley et al., 2018), and management around the motivations to communicate, methods to maintain and manage integrity and ways to balance individual and institutional identities may also be fruitful in some large-scale inter-organizational projects involving varying funding initiatives.

\section{Notes}

1. http://www.aka.fi/en/strategic-research-funding/src-in-brief/

2. https://www.aka.fi/en/strategic-research-funding/blogeja/2018/new-models-for-evaluating-societalimpact-in-strategic-research-programmes-in-finland/ 


\section{References}

Aula, P. (2016), "Reputation change", in Caroll, C. (Ed.), The SAGE Encyclopedia of Corporate Reputation, Sage, Thousand Oaks, CA, pp. 629-632.

Autzen, C. and Weitkamp, E. (2019), "Science communication and public relations: beyond borders", in Dascal, M., Gloning, T. and Lessmollman, A. (Eds), Science Communication, De Gruyter, Berlin, pp. 465-484.

Autzen, C. (2014), "Press releases - the new trend in science communication", Journal of Science Communication, Vol. 13 No. 3, pp. 1-8.

Besley, J.C., Dudo, A. and Yuan, S. (2018), "Scientists' views about communication objectives", Public Understanding of Science, Vol. 27 No. 6, pp. 708-730.

Borchelt, R.E. and Nielsen, K.H. (2014), "Public relations in science", in Bucchi, M. and Trench, B. (Eds), Routledge Handbook of Public Communication of Science and Technology, 2nd ed., Routledge, London and NY, pp. 58-70.

Bowman, T.D. (2015), Investigating the Use of Affordances and Framing Techniques by Scholars to Manage Personal and Professional Impressions on Twitter (Dissertation), Indiana University, Bloomington, IN.

Brass, K. and Rowe, D. (2009), "Knowledge limited: public communication, risk and university media policy", Continuum, Vol. 23 No. 1, pp. 53-76.

Braun, V. and Clarke, V. (2006), "Using thematic analysis in psychology", Qualitative Research in Psychology, Vol. 3 No. 2, pp. 77-101.

Bucchi, M. (2015), "Norms, competition and visibility in contemporary science: the legacy of Robert K. Merton”, Journal of Classical Sociology, Vol. 15 No. 3, pp. 233-252.

Casini, S. and Neresini, F. (2013), "Behind closed doors. Scientists' and science communicators' discourses on science in society. A study across European research institutions", TECNOSCIENZA: Italian Journal of Science and Technology Studies, Vol. 3 No. 2, pp. 37-62.

Cheek, J. and Øby, E. (2019), “Getting attention’ creating and presenting the visible, online, researcher self”, Qualitative Inquiry, Vol. 25 No. 6, pp. 571-582.

Chubb, J. and Watermeyer, R. (2017), "Artifice or integrity in the marketization of research impact? Investigating the moral economy of (pathways to) impact statements within research funding proposals in the UK and Australia”, Studies in Higher Education, Vol. 42 No. 12, pp. 2360-2372.

Claessens, M. (2014), "Research institutions: neither doing science communication nor promoting 'public' relations", JCOM - Journal of Science Communication, Vol. 13. No. 3, pp. 1-5.

Clarke, V. and Braun, V. (2014), "Thematic analysis", in Teo, T. (Ed.), Encyclopedia of Critical Psychology, Springer, New York, pp. 1947-1952.

Corbin, J. and Strauss, A. (2015), Basics of Qualitative Research: Techniques and Procedures for Developing Grounded Theory, 4th ed., Sage, Thousand Oaks, CA.

Cortassa, C. (2016), "In science communication, why does the idea of a public deficit always return? The eternal recurrence of the public deficit", Public Understanding of Science, Vol. 25 No. 4, pp. 447-459.

Couldry, N. and Hepp, A. (2017), The Mediated Construction of Reality, Polity Press, Cambridge.

Davies, S. (2008), "Constructing communication: talking to scientists about talking to the public", Science Communication, Vol. 29 No. 4, pp. 413-434.

Davies, S.R. and Horst, M. (2016), Science Communication: Culture, Identity and Citizenship, Springer, London.

Dreher, S. (2014), "Social media and the world of work: a strategic approach to employees' participation in social media”, Corporate Communications: An International Journal, Vol. 19 No. 4, pp. 344-356.

Exploring the intersections

$-$ 
$\mathrm{JCOM}$ 24,3

Dudo, A., Kahlor, L., AbiGhannam, N., Lazard, A. and Liang, M. (2014), "An analysis of nanoscientists as public communicators”, Nature Nanotechnology, Vol. 9 No. 10, pp. 841-844.

Edwards, L. (2018), Understanding Public Relations: Theory, Culture and Society, Sage, London.

Fähnrich, B. (2017), "Science diplomacy: investigating the perspective of scholars on politics-science collaboration in international affairs", Public Understanding of Science, Vol. 26 No. 6, pp. 688-703.

Fleetwood, S. (2005), "Ontology in organization and management studies: a critical realist perspective”, Organization, Vol. 12 No. 2, pp. 197-222.

Forementin, D. and Bortree, D. (2018), "Giving from the heart: exploring how ethics of care emerges in corporate social responsibility”, Journal of Communication Management, Vol. 23 No. 1, pp. 2-17.

Glaser, B.G. (1963), "The local-cosmopolitan scientist”, American Journal of Sociology, Vol. 69 No. 3, pp. 249-259.

Grand, A., Holliman, R., Collins, T. and Adams, A. (2016), “We muddle our way through': shared and distributed expertise in digital engagement with research", Journal of Science Communication, Vol. 15 No. 4, pp. 1-23.

Heap, T. and Minocha, S. (2012), "An empirically grounded framework to guide blogging for digital scholarship”, Research in Learning Technology, Vol. 20, pp. 176-188.

Heidenreich, S. (2018), "Outreaching, outsourcing, and disembedding: how offshore wind scientists consider their engagement with society", Science, Technology, and Human Values, Vol. 43 No. 3, pp. 464-486.

Horst, M. (2013), "A field of expertise, the organization, or science itself? Scientists' perception of representing research in public communication", Science Communication, Vol. 35 No. 6, pp. 758-779.

Howell, E.L., Nepper, J., Brossard, D., Xenos, M.A. and Scheufele, D.A. (2019), "Engagement present and future: graduate student and faculty perceptions of social media and the role of the public in science engagement", PloS One, Vol. 14 No. 5, pp. 1-20.

Kang, M. and Sung, M. (2017), "How symmetrical employee communication leads to employee engagement and positive employee communication behaviors: the mediation of employeeorganization relationships", Journal of Communication Management, Vol. 21 No. 1, pp. 82-102.

Karmowska, J., Child, J. and James, P. (2017), "A contingency analysis of precarious organizational temporariness", British Journal of Management, Vol. 28 No. 2, pp. 213-230.

Karvonen, E., Kortelainen, T. and Saarti, J. (2014), Julkaise Tai Tuhoudu! Johdatus Tieteelliseen Viestintään, Tampere, Vastapaino.

Karvonen, E. (1999), "Perspektiivinen realismi - parempi perustus kansalaisjournalismille?", Tiedotustutkimus, Vol. 2 No. 22, pp. 44-59.

Kennedy, A.K. and Sommerfeldt, E.J. (2015), "A postmodern turn for social media research: theory and research directions for public relations scholarship", Atlantic Journal of Communication, Vol. 23 No. 1, pp. 31-45.

Koh, E.J., Dunwoody, S., Brossard, D. and Allgaier, J. (2016), "Mapping neuroscientists' perceptions of the nature and effects of public visibility", Science Communication, Vol. 38 No. 2, pp. 170-196.

Kvale, S. and Brinkmann, S. (2009), InterViews: Learning the Craft of Qualitative Research Interviewing, 2nd ed., Sage, Thousand Oaks, CA.

Lo, Y. and Peters, H.P. (2016), "Blogging by scientists: a rare and peripheral activity", 14th International Conference on Public Communication of Science and Technology (PCST), Istanbul, Turkey, available at: http://pcst.co/archive/.

Lomborg, S. (2017), “A state of flux: histories of social media research", European Journal of Communication, Vol. 32 No. 1, pp. 6-15. 
Marcinkowski, F., Kohring, M., Fürst, S. and Friedrichsmeier, A. (2014), "Organizational influence on scientists' efforts to go public: an empirical investigation”, Science Communication, Vol. 36 No. 1 , pp. 56-80.

Mason, J. (2004). "Semistructured interview", in Lewis-Beck, M., Bryman, A. and Futing Liao, T. (Eds), The Sage Encyclopedia of Social Science Research Methods, Sage, Thousand Oaks, CA, p. 1021.

McClain, C. and Neeley, L. (2014), "A critical evaluation of science outreach via social media: its role and impact on scientists", F1000Research, Vol. 3, p. 300.

Merton, R.K. (1973), "Multiple discoveries as strategic research site", in Merton, R.K. (Ed.), The Sociology of Science: Theoretical and Empirical Investigations, University of Chicago Press, Chicago, IL, pp. 371-382.

Mustajoki, A. (2017), "Tutkimuksen yhteiskunnallisen vaikuttavuuden eettisiä kysymyksiä", Tieteessä tapahtuu, Vol. 35 No. 5, pp. 3-13.

Nærland, T.U. (2016), "Colonising the academy? Organisational mediatisation and public research institutions in Norway", MedieKultur: Journal of media and communication research, Vol. 32 No. 60, pp. 123-143.

Overton-de Klerk, N. and Verwey, S. (2013), "Towards an emerging paradigm of strategic communication: core driving forces", Communication, Vol. 39 No. 3, pp. 362-382.

Peters, H.P., Heinrichs, H., Jung, A., Kallfass, M. and Petersen, I. (2008), "Medialization of science as a prerequisite of its legitimization and political relevance", in Donghong, C., Claessens, M., Gascoigne, T., Metcalfe, J., Schiele, B. and Shi, S. (Eds), Communicating Science in Social Contexts, Springer, Dordrecht, pp. 71-92.

Peters, H.P. (2013), "Gap between science and media revisited: scientists as public communicators", Proceedings of the National Academy of Sciences of the United States of America, Aug 2013, Vol. 110 Supplement 3, pp. 14102-14109.

Phillips, L.M. and Brabham, D.C. (2012), "How today's digital landscape redefines the notion of power in public relations", PRism, Vol. 9 No. 2, pp. 1-17.

Rödder, S. (2012), “The ambivalence of visible scientists", The Sciences' Media Connection-Public Communication and its Repercussions, Springer, Dordrecht, pp. 155-177.

Rowe, G. and Watermeyer, R.P. (2018), "Dilemmas of public participation in science policy", Policy Studies, Vol. 39 No. 2, pp. 204-221.

Schäfer, M.S. (2012), "Online communication on climate change and climate politics: a literature review”, Wiley Interdisciplinary Reviews: Climate Change, Vol. 3 No. 6, pp. 527-543.

Scheu, A.M.andOlesk, A.(2018), "National contextual influences on mediatization: the comparison of science decision makers in Estonia and Germany", Science Communication, Vol. 40 No. 3, pp. 366-392.

Sousa, F.J. (2010), "Metatheories in research: positivism, postmodernism, and critical realism", in Woodside, A. (Ed.), Organizational Culture, Business-To-Business Relationships, and Interfirm Networks, Emerald Group Publishing, UK, pp. 455-503.

Tench, R., Verhoeven, P. and Juma, H. (2015), "Turn around when possible: mapping European communication competences", Studies in Media and Communication, Vol. 3 No. 2, pp. 94-108.

TNS BMRB (2015), Factors Affecting Public Engagement by Researchers: A Study on Behalf of a Consortium of UK Research Funders, TNS BMRB and Policy Studies Institute, London, available at: https://wellcome.ac.uk/sites/default/files/wtp060033_0.pdf.

Trench, B. (2012), "Scientists' blogs: glimpses behind the scenes", in Rödder, S., Franzen, M. and Weingart, P. (Eds), The Sciences' Media Connection -Public Communication and its Repercussions. Sociology of the Sciences Yearbook, Vol. 28, Springer, Dordrecht, pp. 273-289.

Väliverronen, E. (2015), "Tiedeviestintä ja asiantuntijuus - tutkijoiden muuttuva suhde julkisuuteen", Yhteiskuntapolitiikka, Vol. 80 No. 3, pp. 221-232.

van Zoonen, W., van der Meer, Toni, G. and Verhoeven, J. (2014), "Employees work-related socialmedia use: his master's voice", Public Relations Review, Vol. 40 No. 5, pp. 850-852.

Exploring the intersections 
$\mathrm{JCOM}$ 24,3

Veletsianos, G., Kimmons, R., Belikov, O. and Johnson, N. (2018), "Scholars' temporal participation on, temporary disengagement from, and return to Twitter", First Monday, Vol. 23 No. 11.

Watermeyer, R. and Lewis, J. (2018), "Institutionalizing public engagement through research in UK universities: perceptions, predictions and paradoxes concerning the state of the art", Studies in Higher Education, Vol. 43 No. 9, pp. 1612-1624.

Weick, K.E., Sutcliffe, K.M. and Obstfeld, D. (2005), "Organizing and the process of sensemaking", Organization Science, Vol. 16 No. 4, pp. 409-421.

Weingart, P. and Joubert, M. (2019), "The conflation of motives of science communication-causes, consequences, remedies", Journal of Science Communication, Vol. 18 No. 3, p. Y01.

Wilkinson, C. and Weitkamp, E. (2013), "A case study in serendipity: environmental researchers use of traditional and social media for dissemination”, PloS One, Vol. 8 No. 12, e84339.

Wilkinson, C., Bultitude, K. and Dawson, E. (2010), "Oh yes, robots! People like robots; the robot people should do something: perspectives and prospects in public engagement with robotics", Science Communication, Vol. 33 No. 3, pp. 367-397.

Wilkinson, C. (2017), "Evidencing impact: a case study of UK academic perspectives on evidencing research impact", Studies in Higher Education, Vol. 44 No. 1, pp. 1-14.

Yuan, S., Besley, J.C. and Dudo, A. (2019), "A comparison between scientists' and communication scholars' views about scientists' public engagement activities”, Public Understanding of Science, Vol. 28 No. 1, pp. 101-118.

Zacharewicz, T., Lepori, B., Reale, E. and Jonkers, K. (2018), "Performance-based research funding in EU Member States - a comparative assessment", Science and Public Policy, Vol. 46 No. 1, pp. 105-115.

\section{Corresponding author}

Kaisu Koivumäki and can be contacted at: kaisu.koivumaki@oulu.fi

For instructions on how to order reprints of this article, please visit our website:

www.emeraldgrouppublishing.com/licensing/reprints.htm

Or contact us for further details: permissions@emeraldinsight.com 